The BDJ News section accepts items that include general news, latest research and diary events that interest our readers. Press releases or articles may be edited, and should include a colour photograph if possible. Please direct your correspondence to the News Editor, Arveen Bajaj at the BDJ, 64 Wimpole Street WIG 8YS or by email to bdj@bda.org

\section{Change ahead}

A new report on delivering change in NHS dentistry was revealed by Health Secretary John Reid recently. Under the reforms the equivalent of 1,000 dentists will be recruited by October 2005 with 650 of these being new recruits, either from home or abroad.

They will be recruited through a number of routes, such as dentists increasing their level of commitment to the NHS, attracting dentists to return to the NHS from career breaks by a better deal and more flexible working, recruiting via an international recruitment programme, targeting dentists from the EU and by speeding up the process for overseas dentists to register to work in the UK.

The Government will also fund 170 extra undergraduate dental training places in England from October 2005, a capital investment of £80m over four years to support this expansion and by 2005/6, NHS dentistry will receive extra funding of over $£ 250 \mathrm{~m}$ a year. It adds that in recognition of the additional work and training dentists and their practice staff will need to prepare for changes, an extra £9 million will be provided to help dental practices prepare.

Reforms will be introduced to modernise the dentistry profession for the 21st century through a new dentists contract making it possible for them to spend more time with patients and encourage preventative care, using the skills of the entire dental team more efficiently. New roles for hygienists and dental nurses and local Primary Care Trusts (PCTs) will use the £1.6 billion devolved budget to ensure that local expenditure on dentistry is sustained.

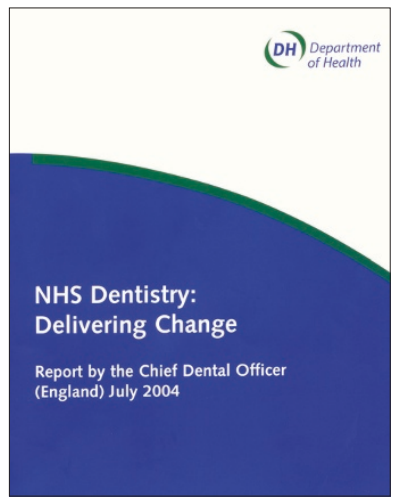

\section{Athenian honour}

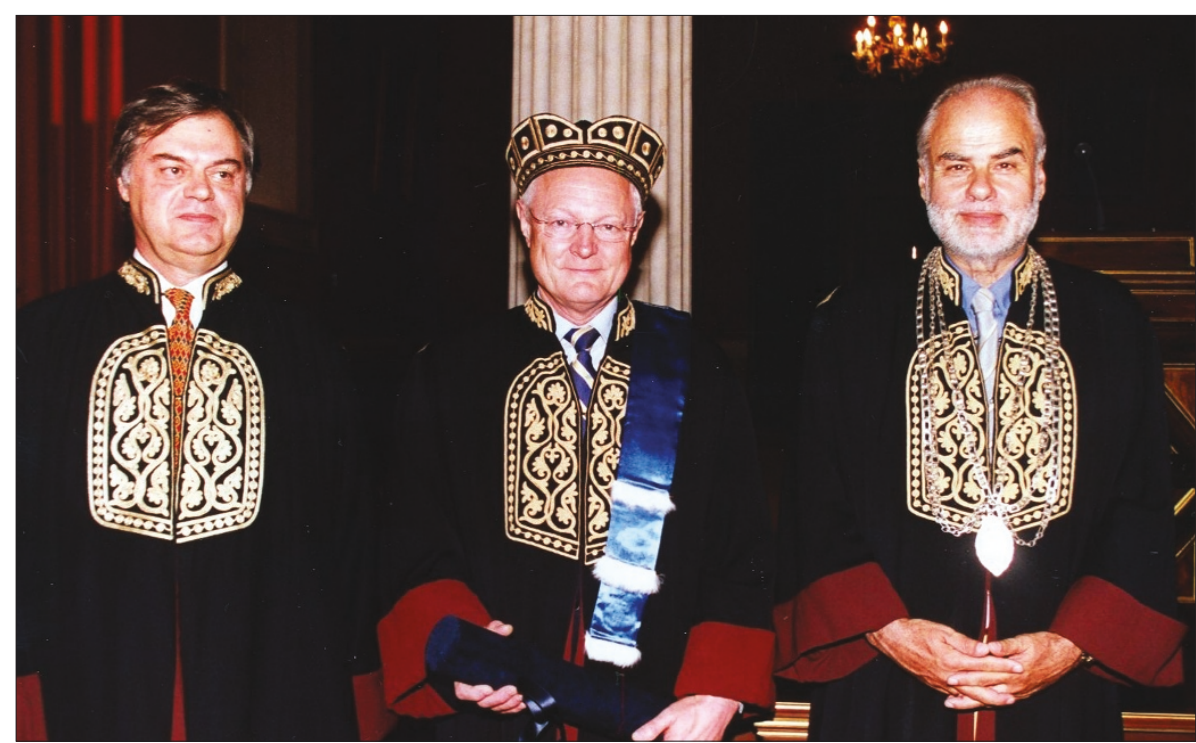

Professor of Oral Maxillofacial Surgery Professor John Langdon was recently awarded an Honorary Doctorate by the National and Kapodistrian University of Athens, Greece, one of the oldest universities in Europe. The award was in recognition of outstanding achievements in the knowledge and practice of his specialty. The ceremony took place in the Athens University Great Hall. Above, left to right: Professor Vougiouklakis, Dean of the Dental School of Athens Kapodistrian University, Professor J D Langdon and Professor Kittes, Vice Principal of the Athens Kapodistrian University.

\section{Reducing NHS bureaucracy}

The number of NHS bodies that work at 'arm's length' from the Department of Health (DoH) are to be merged, abolished or see their functions streamlined in a bid to minimise bureaucracy and save money, according to Health Secretary John Reid. The changes form the second stage of the DoH's plans to overhaul the way it works with stakeholders in the health and social care system and aims to save at least $£ 500$ million in funds. It claims that the increasing resources can be channelled directly to frontline NHS patient care.

Dr Reid added that though the arm's length body sector had done a lot of good work, it had grown over several decades and no longer met current health and social care needs or those of future generations.

The number of DoH arm's length bodies will be reduced by almost half from 38 to 20 and will see a 25 per cent reduction

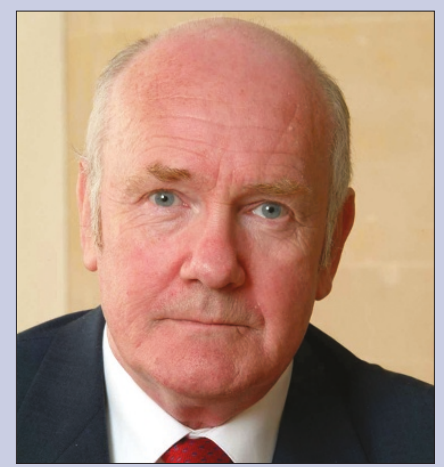

Health Secretary John Reid

in staff working in the sector by 2008 .

Some of the bodies being considered in the review include the Council for the Regulation of Health Care Professionals, the Dental Practice Board, the Dental Vocational Training Authority, the Health Development Agency, the National Radiological Protection Board and the Dental Special Health Authority. 


\section{DIARY}

August 2004

8th Congress of the International Congress of Oral Implantologists - Asia Pacific Section \& International Symposium of the Asian Oral Implant Academy

Date: 27-29.08.04

Venue: The New Otani, Singapore

Contact: Meeting secretariat

Tel: 67343162

Fax: 67321979

Email: singdent@singdent.com.sg http://web.singnet.com.sg/ qualiser/me eting.html

\section{September 2004}

IFEA Sixth Endodontic World Congress

Date: 8-11.09.04

Venue: Brisbane Convention and

Exhibition Centre, Queensland, Australia

Tel: (0)7 38585599

Email: ifea2004@im.com.au

www.ifea2004.im.com.au

92nd FDI World Dental Congress

Date: 10-13.09.04

Venue: Delhi, India

Tel: +91 1123315834

Email: shastri@tci.co.in

www.fdiworldental.org

Cleft care and the patient in the UK, Europe and Beyond

Date: 14.09 .04

Venue: Royal Society of Medicine

Contact: Cleft Lip and Palate Association

Tel: +44 (0)207 8334883

Email: info@clapa.com

www.clapa.com

\section{Winning entry}

Dr Nigel Willmott, a senior house officer in the Department of Paediatric Dentistry at the Royal London Hospital has won the British Society of Dental Research 2004 Senior Colgate Prize.

Dr Willmott presented his work on 'X-Ray Microtomographic Study Of Dentinal Caries In Deciduous Molars' in the BSDR Scientific Meeting held in Birmingham, where he showed a rotating 3-D image of a carious deciduous tooth (pictured).

Dr Willmott carried out his research as a Master of Clinical Dentistry student in the Centre of Oral Growth and Development.

The high definition X-ray microtomography system was developed by $\mathrm{Dr}$ Davis and Professor James Elliott, the head of the centre. The system has been widely used for research in biological hard tissue and material sci-

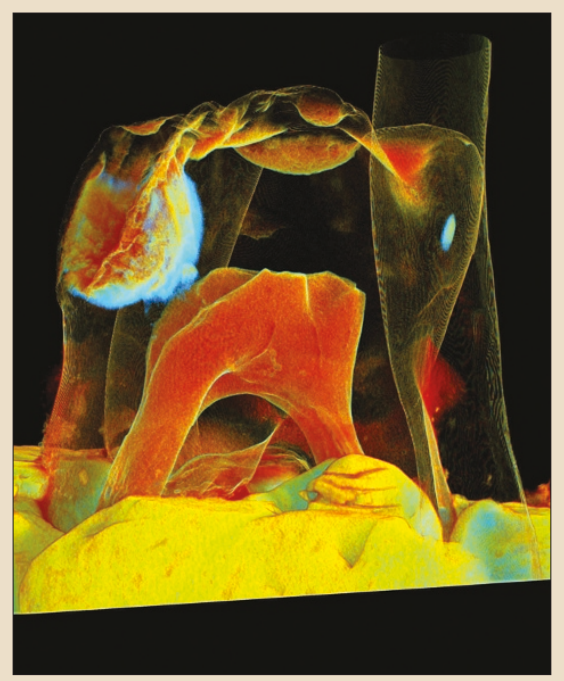

ence. The moving image can be viewed by visiting the website at http://www.smd.qmul.ac.uk/dental/bip /xmt/gallery.htm.

\section{European hygienists registration}

New regulations mean that hygienists from Europe who hold European passports (and do not hold a recognised dental qualification) can now apply to have their application for GDC registration assessed on the basis of their knowledge and experience.

The new panel to assess European hygienists will next meet on 17 August. The Registration Working Group also met on 14 July to look at (future) assessment processes for PCD groups, who are yet to be registered with the Council.

The renewal period for temporary registration is now underway, when approximately 200 dentists will apply to renew their temporary registration. The Registration team is also preparing for the pilot scheme which will allow temporary registrants waiting to do part C of the IQE to work in a primary care setting.

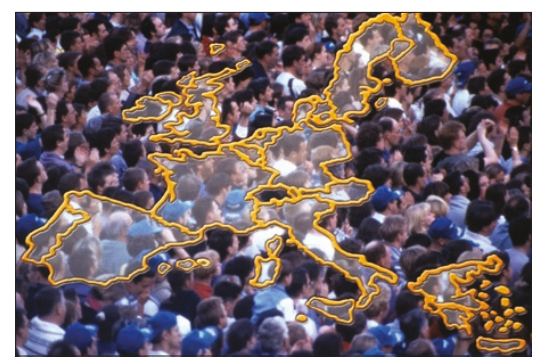




\section{Did you treat this man?}

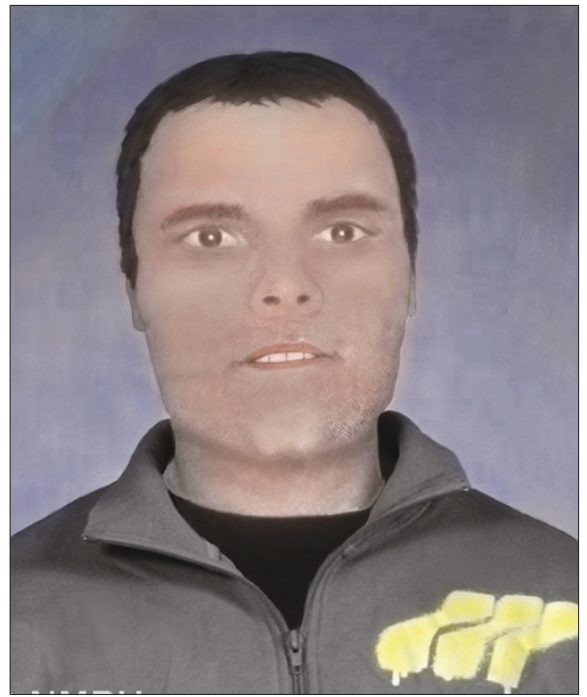

A computer generated image of the individual.

Thames Valley Police are requesting the help of dentists to identify a man whose body was found in the Jubilee River near Maidenhead, Berkshire, on 1 May 2004.

The man had been dead for at least two weeks and carried no identification, had no distinguishing marks or features and had not been reported missing. Extensive enquiries have so far failed to establish who he was.

A post mortem dental identification was carried out by a forensic odontologist, who found the man's dental structures to be in a good state of preservation. Oral hygiene was of a good standard and staining of the teeth was minimal, indicating that the man was probably a non-smoker.

The individual had had a lot of routine restorative dentistry carried out. All the fillings were in composite material; there were no amalgam restorations present. This would indicate that the dentistry had been carried out privately rather than on the National Health Service. There were early signs of decay in the upper left canine tooth, which may mean the man had not visited a dentist in the past year. A detailed version of the post mortem dental identification report is available on request.

A computerised image (above) of the man's face has been produced by a facial reconstruction expert and several appeals have been made through the media, with no success. The man was white, in his mid-twenties to mid-thirties, $6 \mathrm{ft}$ 1in, medium to well built, with short brown hair. Anyone who has information that could help identify the man is asked to contact Det Sgt Nick Burleigh of Slough CID on 08458505 505, or by e-mail at Nick.burleigh@thamesvalley.pnn.police.uk.

(Images courtesy of the National Missing Persons Helpline and Thames Valley Police.)

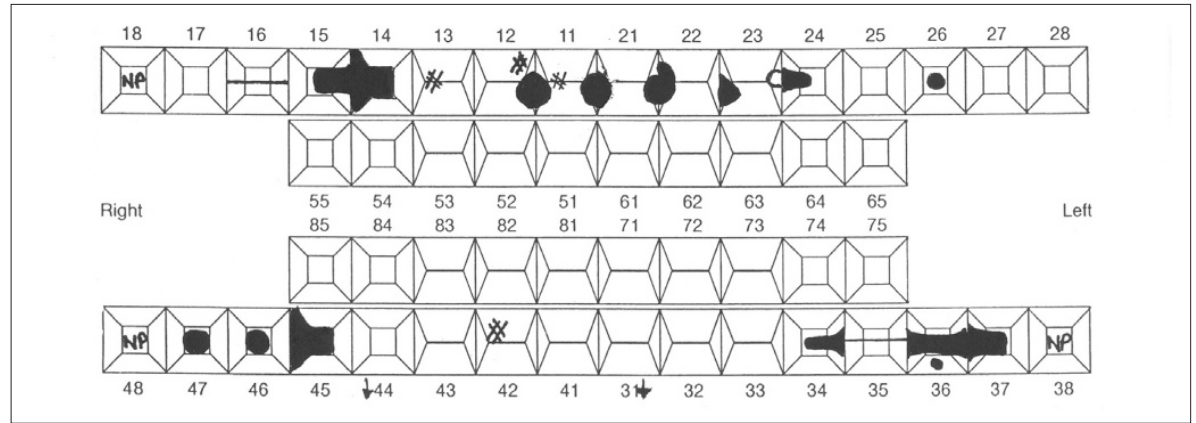

Dental chart

\section{Complaints scheme director appointed}

The GDC has appointed a Director to lead and manage the implementation and operation of the Council's new non-NHS Complaints Scheme.

Gordon Miles is currently Head of Stakeholder Relations at the Dental Practice Board and, most recently, has been on secondment to the Department of Health on the Modernising Dentistry change programme. Currently there is no equivalent to the NHS complaints schemes for private dentistry in the UK.

This new scheme will deal with complaints about non-NHS dental care. It is hoped that it will save many patients time and expense in pursuing other avenues of complaint, such as legal proceedings or the GDC's fitness to practise procedures (which focus on fitness for registration and do not offer opportunities for mediation and complaints resolution).

The scheme will be run and funded by the GDC, but will be completely separate from the GDC's fitness to practise procedures.

The Director will report to the GDC's Chief Executive, and work with an advisory board. A report of the scheme will be published annually which will be considered by the GDC. 